\title{
Dengue virus serotype 4 and chikungunya virus coinfection in a traveller returning from Luanda, Angola, January 2014
}

R Parreira (Ricardo@ihmt.unl.pt) ${ }^{1}$, S Centeno-Lima ${ }^{2}$, A Lopes ${ }^{1}$, D Portugal-Calisto ${ }^{3}$, A Constantino $0^{4,5}$, J Nina $^{3,6}$

1. Unidade de Microbiologia Médica (Grupo de Virologia) and Unidade de Parasitologia e Microbiologia Médicas (UPMM), Instituto de Higiene e Medicina Tropical (IHMT), Universidade Nova de Lisboa (UNL), Lisbon, Portugal

2. Unidade de Clínica Tropical and Centro de Malária e Outras Doenças Tropicais (CMDT), Instituto de Higiene e Medicina Tropical (IHMT), Universidade Nova de Lisboa (UNL), Lisbon, Portugal

3. Unidade de Clínica Tropical IHMT/UNL, Lisbon, Portugal

4. St. Maria Hospital-Centro Hospitalar Lisboa Norte, Lisbon, Portugal

5. São Francisco Xavier Hospital-Centro Hospitalar Lisboa Ocidental, Lisbon, Portugal

6. Centro Hospitalar de Lisboa Ocidental/Hospital de Egas Moniz, Lisbon, Portugal

Parreira R, Centeno-Lima S, Lopes A, Portugal-Calisto D, Constantino A, Nina J. Dengue virus serotype 4 and chikungunya virus coinfection in a traveller returning from Luanda, Angola, January 2014. Euro Surveill. 2014;19(10): pii=20730. Available online: http://www.eurosurveillance.org/ViewArticle.aspx?Articleld=20730

A concurrent dengue virus serotype 4 and chikungunya virus infection was detected in a woman in her early 50 s returning to Portugal from Luanda, Angola, in January 2014. The clinical, laboratory and molecular findings, involving phylogenetic analyses of partial viral genomic sequences amplified by RT-PCR, are described. Although the circulation of both dengue and chikungunya viruses in Angola has been previously reported, to our knowledge this is the first time coinfection with both viruses has been detected there.

\section{Detection of coinfection}

Here we report the simultaneous detection of chikungunya virus (CHIKV) and dengue virus (DENV) genomes in the peripheral blood of a traveller who returned from Luanda, Angola, to Portugal in January 2014.

The traveller, a woman in her early 50s, was born and raised in Angola and has lived in Lisbon, Portugal, since the early 1990s. She stayed in Luanda from midDecember 2013 to early January 2014 at her family's place of residence. There were a large number of mosquitoes in the garden and the patient was repeatedly bitten during her stay.

The patient reported feeling unwell in early January, two days before her return to Portugal. Her condition worsened during the flight, and in the next few days she had high fever (up to $39.5{ }^{\circ} \mathrm{C}$ ), severe arthralgia, myalgia, prostration and abdominal pain. Three days after her return, she went to the emergency department of a hospital: a malaria blood smear was negative and among a range of laboratory tests (including coagulation speed and levels of glucose, creatinine, bilirubin, aspartate transaminase (AST), alanine transaminase (ALT), lactate dehydrogenase (LDH), sodium, potassium, chloride ions and C-reactive protein), the only abnormal findings were a mildly low platelet count (139 $\times 10^{9} / \mathrm{L}$; norm: $\left.150-400 \times 10^{9} / \mathrm{L}\right)$ and mild leucopenia $\left(2.9 \times 10^{9} / \mathrm{L}\right.$; norm: 4-10 $\left.\times 10^{9} / \mathrm{L}\right)$. The following day, she went to a hospital specialised in tropical diseases, where photophobia was detected. Further tests were carried out (described below). An arbovirus infection was suspected as the malaria blood smear was persistently negative.

Four days later, the fever had subsided and her condition improved progressively over the next two to three weeks. The patient did not have a rash, conjunctivitis or other clinical signs of a complicated dengue infection (DENV infection with haemorrhage); indeed, she had no other abnormal clinical signs at all during the course of her illness. To the best of her knowledge, none of her family or neighbours in Luanda experienced a similar illness.

\section{Laboratory findings}

Four days after her return from Luanda, DENV nonstructural (NS) protein 1 and anti-CHIKV IgM were detected (through the use of SD BIOLINE Dengue Duo NS1 Ag + Ab Combo and SD Bioline Chikungunya IgM), while DENV-specific IgM and IgG were not detected. Two days later, the same tests were performed: anti-CHIKV IgM and DENV-specific IgM and IgG were detected, but DENV NS1 was not. Using RNA extracted from the blood sample where NS1 had been found, detection of the viral genomes was carried out either by a nested RT-PCR as previously described $[1,2]$ or by using primers that target the virus packaging sequence [3]. The sizes of the amplicons obtained were compatible with the presence of both DENV4 (approximately $390 \mathrm{bp}$, covering the C-prM region) and CHIKV (approximately $350 \mathrm{bp}$, in the NS2 coding region). 
Additional molecular confirmation was obtained by performing phylogenetic analyses of the sequence of both amplicons (deposited in the GenBank/European Molecular Biology Laboratory (EMBL)/DNA DataBank of Japan (DDBJ) databases under accession numbers $A B 908053$ and $A B 908054$ ) using the using $G T R+G+1$ model [4]. The DENV sequence obtained clearly clustered with DENV4 reference strains (Figure 1), while the CHIKV sequence segregated with those included in the Central/Eastern/Southern African genotype (Figure 2). Despite the presence of both viral genomes in the same blood sample, the viraemia dropped rapidly below the detection level, as both DENV and CHIKV RNA could not be detected in blood collected 48 hours later.

\section{Background}

Dengue has developed into a worldwide public health problem, especially over the last 50 years $[5,6]$. More recently, the impact of other arboviruses on human health has followed a similar trend [7]. This is true for CHIKV, which, since 2004, has been an emerging pathogen, causing large outbreaks in many islands in the Indian Ocean and in the Indian subcontinent, where, in 2005-2006 alone, well over a million cases of CHIKV infection were reported from different states [8].

The majority of DENV infections occur in the AsiaPacific and Americas-Caribbean regions [5], while CHIKV is endemic to countries in Africa and Asia [9]. In Africa, the epidemiology and public health impact of both viruses is far from clear, but the wide geographical distribution of their primary vectors (Aedes aegypti and Aedes albopictus), rapid human population growth, unplanned urbanisation, and increased international travel make their transmission likely $[10,11]$. Moreover, as the clinical features of DENV and CHIKV are similar, CHIKV infections usually go undiagnosed in areas where DENV circulates [11]. Furthermore, where malaria is also endemic and the majority of febrile illnesses are diagnosed as such, often without laboratory confirmation, both viral infections may go undetected [12].

Although CHIKV/DENV coinfections were first reported in India in 1967 [13] and later confirmed in Sri Lanka (2008), Malaysia (2010) and Gabon (2007) [14-16], these coinfections are rarely notified.

\section{Discussion}

Serological reports from the 1960 s [17], the detection of DENV in travellers returning from Angola in the 1980 s [10], and the detection of DENV 1 and DENV 2 in travellers in the 1980 s and in 1999-2002 [10,18] suggest endemic DENV activity in Angola. As far as CHIKV is concerned, the situation is a lot less clear. However, serological studies from the 1960 s not only identified the presence of anti-CHIKV neutralising antibodies in the north of the country, but also allowed the isolation of two strains from a viraemic individual and wild-caught mosquitoes during an outbreak of Kâtolu Tôlu (Kimbundu dialect for 'break-bone disease'),
FIGURE 1

Maximum likelihood phylogenetic tree analysis of dengue virus (DENV) serotypes 1-4 C-prM sequences

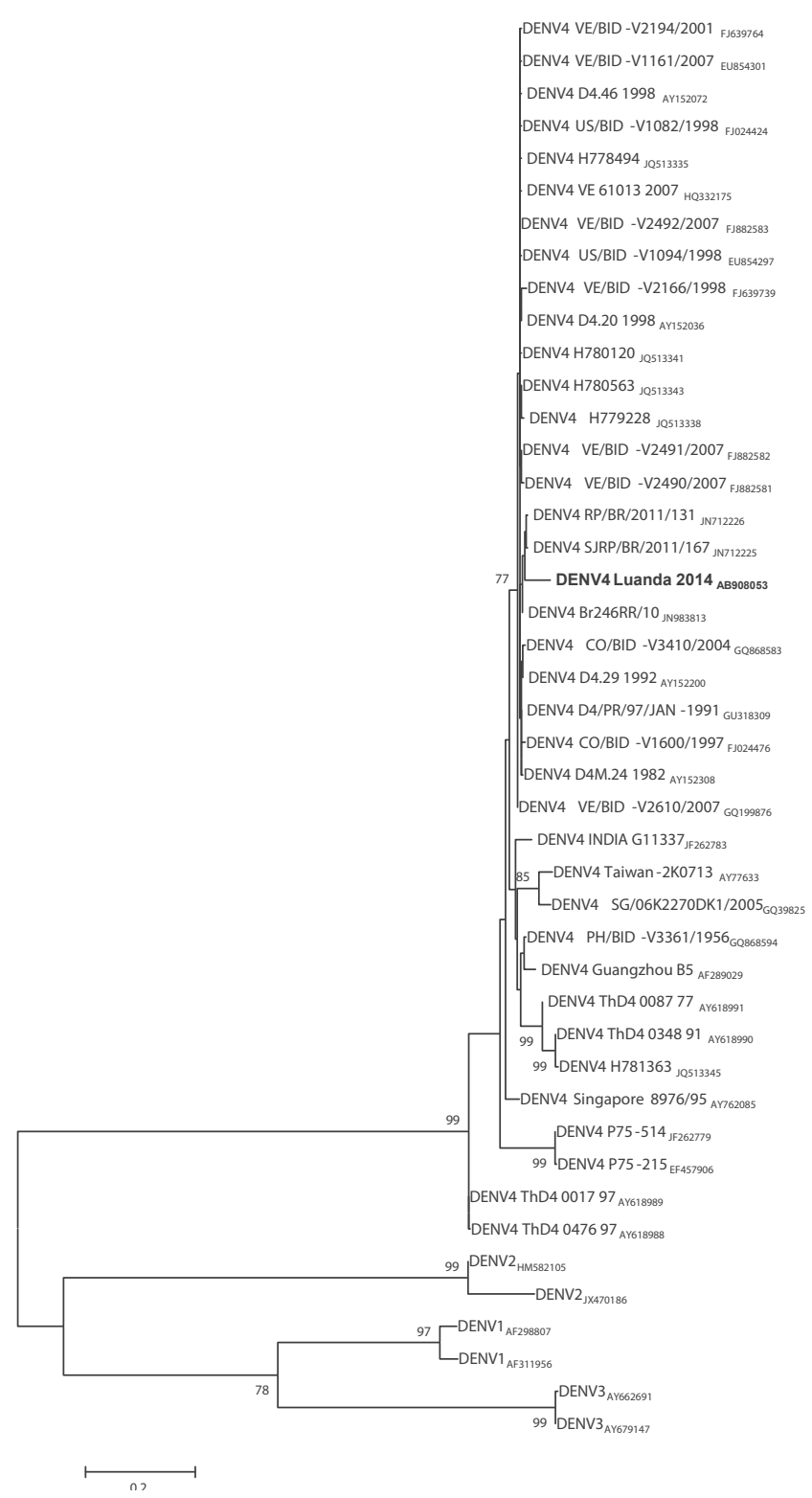

The tree was constructed using the using the $\mathrm{GTR}+\Gamma+I$ model [4]. The amplicon isolated from the patient is shown in bold. Reference strains, downloaded from public databases, are identified by strain name and accession number (DENV4) or simply by viral serotype and accession number (DENV1-3). The numbers at specific branches indicate bootstrap values (only values $\geq 77 \%$ are indicated)

a dengue-like disease caused by the CHIKV, which occurred in Luanda in 1970 [19].

The detection of $\mathrm{DENV}_{4}$ in the recent traveller is of interest, given that on 1 April 2013, the Angolan health authorities reported a dengue outbreak in the country [20], which was later shown to have been caused by DENV1 [21], and the current description of $\mathrm{DENV}_{4}$ in 


\section{FIGURE 2}

Maximum likelihood phylogenetic tree of chikungunya virus (CHIKV) partial nonstructural protein (NS) 2 sequences

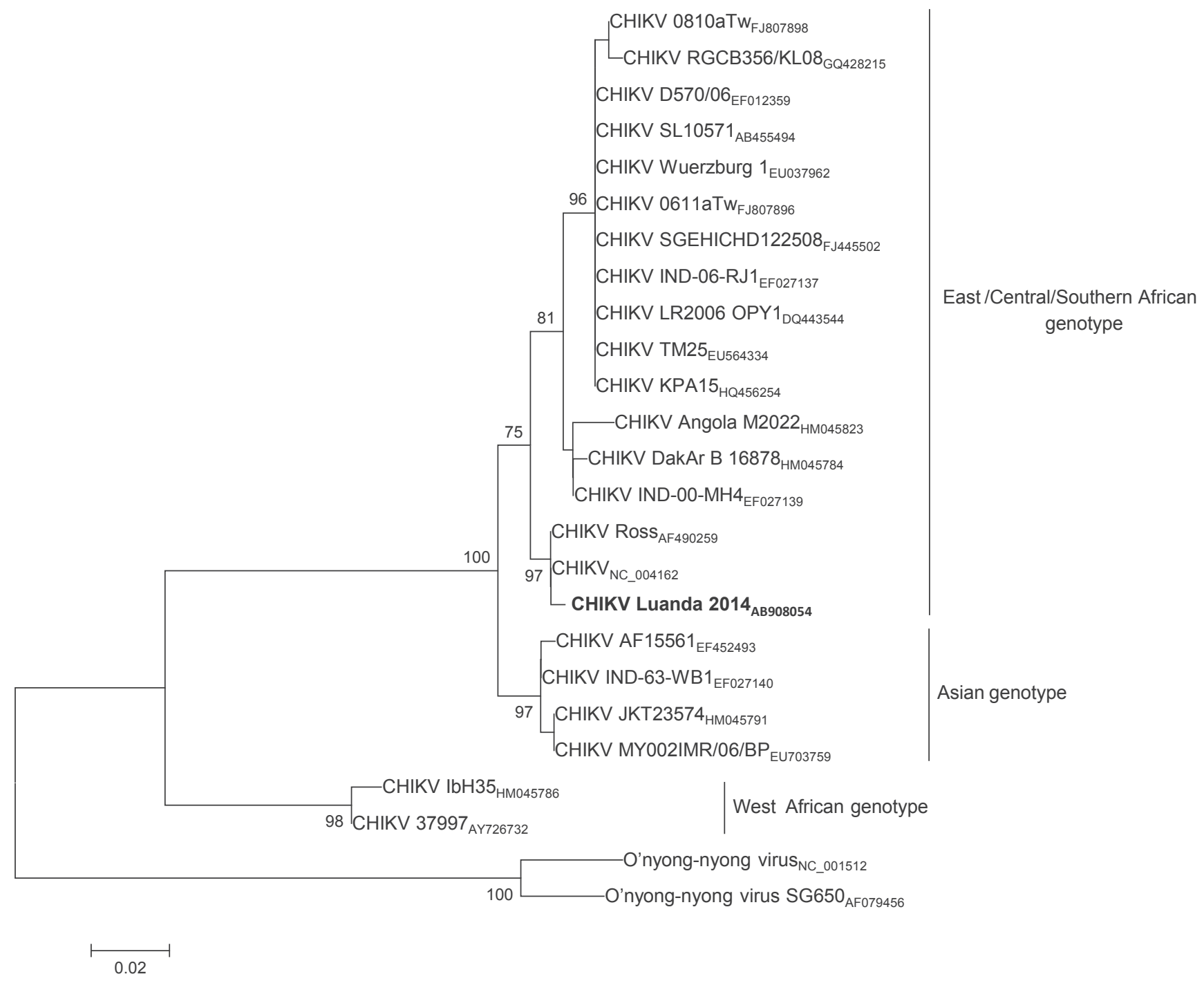

The tree was constructed using the using the $\mathrm{GTR}+\Gamma+\mathrm{I}$ model [4]. The amplicon isolated from the patient is shown in bold. Reference strains are indicated by strain name and accession number. The three CHIKV genotypes (East/Central/Southern African, West African and Asian) are indicated. The numbers at specific branches indicate bootstrap values (values $\geq 75 \%$ are indicated).Two strains of o'nyong nyong virus, the Alphavirus most closely related to CHIKV, have been used as an outgroup.

Luanda may indicate the circulation of multiple DENV subtypes in the country.

Although clinical examination of CHIKV/DENV coinfected patients has not yet allowed the identification of specific or severe symptoms, such observations should be interpreted with caution in view of the limited number of clinical and biological investigations reported. Our findings may add to the recognition of CHIKV/DENV coinfections and suggest that tests to detect the presence of both viruses should be carried out in individuals showing clinical signs of an infection with either CHIKV or DENV.
Conflict of interest

None declared.

\section{Authors' contributions}

Ricardo Parreira: molecular analyses and manuscript writing. Ângela Mendes: molecular analyses. Jaime Nina: clinical diagnosis and manuscript writing. Antónia Constantino: clinical diagnosis and manuscript writing. Sónia CentenoLima and Daniela Portugal Calisto: laboratory diagnosis and manuscript writing. 


\section{References}

1. Harris E, Roberts TG, Smith L, Selle J, Kramer LD, Valle S, et al. Typing of dengue viruses in clinical specimens and mosquitoes by single-tube multiplex reverse transcriptase PCR. J Clin Microbiol. 1998;36(9):2634-39.

2. Lanciotti RS, Calisher CH, Gubler DJ, Chang GJ, Vorndam AV. Rapid detection and typing of dengue viruses from clinical samples by using reverse transcriptase-polymerase chain reaction. J Clin Microbiol. 1992;30(3):545-51.

3. Pimenta A. Identificação da sequência de encapsidação do genoma do virus Chikungunya (CHIKV). [Identification of the chikungunya vírus (CHIKV) genome packaging sequence] [Master's dissertation]. Lisbon: Instituto de Higiene e Medicina Tropical/Universidade Nova de Lisboa, Portugal; 2013. Portuguese.

4. Strimmer K, von Haeseler A. Nucleotide substitution models. In: Salemi M, Vandamme A-M, editors. The phylogenetic handbook: a practical approach to DNA and protein phylogeny. Cambridge: Cambridge University Press; 2003. p. 72-87.

5. Bhatt S, Gething PW, Brady OJ, Messina JP, Farlow AW, Moyes $\mathrm{CL}$, et al. The global distribution and burden of dengue. Nature. 2013;496(7446):504-7. http://dx.doi.org/10.1038/nature12060

6. World Health Organization (WHO). Dengue: guidelines for diagnosis, treatment, prevention and control. Geneva: WHO; 2009. Available from http://whqlibdoc.who.int/ publications/2009/9789241547871_eng.pdf

7. Weaver SC, Barrett AD. Transmission cycles, host range, evolution and emergence of arboviral diseases. Nat Rev Microbiol. 2004;2(10):789-801. http://dx.doi.org/10.1038/nrmicr01006

8. Ravi V. Re-emergence of chikungunya virus in India. Indian J Med Microbiol. 2006;24(2):83-4 http://dx.doi.org/10.4103/0255-0857.25175

9. Naresh Kumar CV, Sai Gopal DV. Reemergence of Chikungunya virus in Indian Subcontinent. Indian J Virol. 2010;21(1):8-17. http://dx.doi.org/10.1007/s13337-010-0012-1

10. Amarasinghe A, Kuritsk JN, Letson GW, Margolis HS. Dengue virus infection in Africa. Emerg Infect Dis. 2011;17(8):1349-54.

11. Caglioti C, Lalle E, Castilletti C, Carletti F, Capobianchi MR, Bordi L. Chikungunya virus infection: an overview. New Microbiol. 2013;36(3):211-27.

12. Amexo M, Tolhurst R, Barnish G, Bates I. Malaria misdiagnosis: effects on the poor and vulnerable. Lancet. 2004:364(9448):1896-8.

http://dx.doi.org/10.1016/S0140-6736(04)17446-1

13. Myers RM, Carey DE. Concurrent isolation from patient of two arboviruses, chikungunya and dengue type 2 . Science. 1967;157(3794):1307-8. http://dx.doi.org/10.1126/science.157.3794.1307

14. Leroy EM, Nkoghe D, Ollomo B, Nze-Nkogue C, Becquart P, Grard G, et al. Concurrent chikungunya and dengue virus infections during simultaneous outbreaks, Gabon, 2007. Emerg Infect Dis. 2009;15(4):591-3. http://dx.doi.org/10.3201/eid1504.080664

15. Hapuarachchi HA, Bandara KB, Hapugoda MD, Williams S, Abeyewickreme W. Laboratory confirmation of dengue and chikungunya co-infection. Ceylon Med J. 2008;53(3):104-5.

16. Nayar SK, Noridah O, Paranthaman V, Ranjit K, Norizah I, Chem YK, et al. Co-infection of dengue virus and chikungunya virus in two patients with acute febrile illness. Med J Malaysia. 2007;62(4):335-6.

17. Kokernot RH, Casaca VM, Weinbren MP, McIntosh BM. Survey for antibodies against arthropod-borne viruses in the sera of indigenous residents of Angola. Trans R Soc Trop Med Hyg. 1965;59(5):563-70.

http://dx.doi.org/10.1016/0035-9203(65)90158-6 http://dx.doi.org/10.1016/0035-9203(65)90159-8

18. Vasconcelos PF, Travassos da Rosa ES, Travassos da Rosa JF, de Freitas RB, Dégallier N, Rodrigues SG, et al. Outbreak of classical fever of dengue caused by serotype 2 in Araguaiana, Tocantins, Brazil. Rev Inst Med Trop Sao Paulo. 1993;35(2):1418. Portuguese.

http://dx.doi.org/10.1590/So036-46651993000200005

19. Filipe AF, Pinto MR. Arbovirus studies in Luanda, Angola. 2. Virological and serological studies during an outbreak of dengue-like disease caused by the Chikungunya virus. Bull World Health Organ. 1973;49(1):37-40.

20. Casos de dengue registados no hospital geral de Luanda. [Dengue cases recorded in the general hospital of Luanda]. ANGONOTÍCIAS. [Accessed 7 May 2013]. Portuguese. Available from: http://www.angonoticias.com/Artigos/item/38122/ casos-de-dengue-registados-no-hospital-geral-de-luanda

21. ProMED-mail. Dengue/DHF update (31): Asia, Africa, Pacific Archive Number: 20130420.1660193. 20 Apr 2013. Available from: http://www.promedmail.org 